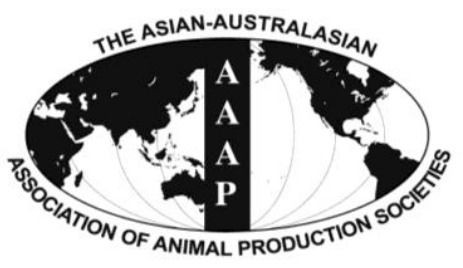

\title{
Molecular Characterization and Expression Analysis of Adrenergic Receptor Beta 2 (ADRB2) Gene before and after Exercise in the Horse
}

\author{
Hyun-Woo Cho ${ }^{\text {a }}$, Sangsu Shin ${ }^{1, a}$, Ki-Duk Song, ${ }^{2, a}$, Jeong-Woong Park, Jae-Young Choi, \\ Hak-Kyo Lee ${ }^{2, *}$, and Byung-Wook Cho* \\ Department of Animal Science, College of Natural Resources and Life Sciences, \\ Pusan National University, Miryang 627-702, Korea
}

\begin{abstract}
The adrenergic receptor beta 2 (ADRB2) plays a role in various physiological responses of the muscle to exercise, such as contraction and relaxation. Given its important role in muscle function, we investigated the structure of the horse $A D R B 2$ gene and its expression pattern after exercise to determine if it can serve as a putative biomarker for recovery. Evolutionary analyses using synonymous and non-synonymous mutation ratios, were compared with other species (human, chimpanzee, mouse, rat, cow, pig, chicken, dog, and cat), and revealed the occurrence of positive selection in the horse ADRB2 gene. In addition, expression analyses by quantitative polymerase chain reaction exhibited ubiquitous distribution of horse ADRB2 in various tissues including lung, skeletal muscle, kidney, thyroid, appendix, colon, spinal cord and heart, with the highest expression observed in the lung. The expression of $A D R B 2$ in skeletal muscle was significantly up-regulated about four folds 30 minutes post-exercise compared to pre-exercise. The expression level of $A D R B 2$ in leukocytes, which could be collected with convenience compared with other tissues in horse, increased until $60 \mathrm{~min}$ after exercise but decreased afterward until $120 \mathrm{~min}$, suggesting the ADRB2 expression levels in leukocytes could be a useful biomarker to check the early recovery status of horse after exercise. In conclusion, we identified horse $A D R B 2$ gene and analyzed expression profiles in various tissues. Additionally, analysis of $A D B R 2$ gene expression in leukocytes could be a useful biomarker useful for evaluation of early recovery status after exercise in racing horses. (Key Words: Adrenergic Receptor Beta 2, Biomarker, Exercise Recovery, Horse, Leukocytes)
\end{abstract}

\section{INTRODUCTION}

Adrenergic receptors play an important role in physiological adaptation of mammalian cells.

\footnotetext{
* Corresponding Authors: Hak-Kyo Lee. Tel: +82-31-670-5656 Fax: +82-31-670-5671, E-mail: breedlee@empas.com / ByungWook Cho. Tel: +82-55-350-5515, Fax: +82-55-350-5519; E-mail: bwcho@pusan.ac.kr

${ }^{1}$ Life and Industry Convergence Research Institute,College of Natural Resources and Life Sciences, Pusan National University, Miryang 627-702, Korea.

${ }^{2}$ Genomic informatics Center, Hankyong National University, Anseong 456-749, Korea.

${ }^{a}$ These authors contributed equally to this work.

Submitted Jul. 29, 2014; Revised Aug. 28, 2014; Accepted Sept. 23, 2014
}

Catecholamines interact with adrenergic receptors $(\alpha$ and $\beta$ receptors), which stimulate the sympathetic nervous system. These receptors belong to the G-protein-coupled receptor family (McGraw and Liggett, 2005). Activation of Gprotein causes the intracellular concentration of the secondary messenger cyclic adenosine monophosphate to increase, resulting in heart muscle contraction, smooth muscle relaxation and glycogenolysis (Rang et al., 2003).

Adrenergic receptor beta 2 (ADRB2) stimulation leads to the activation of both stimulatory and inhibitory $\alpha$ subunits of the guanosine triphosphate activated protein. Also, many studies of $A D R B 2$ gene have suggested that genetic influence is caused by non-synonymous single nucleotide polymorphism. The Arg16/Gly16 polymorphism might also associate with endurance during exercise 
(Wolfarth et al., 2007). Moreover, ADRB2 is associated with human peripheral blood, physiological response to exercise, and recovery (Zieker et al., 2005; MacNeil et al., 2010). Despite the established importance of the ADRB2 gene in muscle function, its structure and expression have not been reported in horse.

In previous study, we conducted RNA-sequencing in skeletal muscle of six Thoroughbred horses before and after exercise, and found the fold-change value of $A D R B 2$ gene was increased significantly after exercise (Park et al., 2012). The objective of this study was to investigate the sequence and expression pattern of the $A D R B 2$ gene in various horse tissues and leukocytes to evaluate the gene as a biomarker on the recovery of racing horse.

\section{MATERIALS AND METHODS}

\section{Tissue and blood samples}

Blood samples were obtained from three thoroughbred horses, which were maintained at the Ham-an Racing Horse Resort and Training Center, South Korea. Blood was collected before and after trotting on a treadmill at $30 \mathrm{~min}$ intervals from 30 to $120 \mathrm{~min}$. The National Institute of Subtropical Agriculture, Rural Development Administration, provided three Jeju horses, which were used for tissue sampling. Skeletal muscle, kidney, thyroid, lung, appendix, colon, spinal cord and heart tissues were stored in a liquid nitrogen tank until RNA extraction was done. All procedures were conducted by following the protocol that had been reviewed and approved by the Institutional Animal Care and Use Committee at Pusan National University (protocol numbers: PNU-2014-0644, PNU-2014-0645).

\section{Bioinformatic analysis}

The ADRB2 genomic DNA and amino acid sequences of various species (horse, human, chimpanzee, mouse, rat, cow, pig, chicken, dog, and cat) were retrieved from the Ensemble database (http://www.ensembl.org/) and aligned with BioEdit software using the ClustalW method. Phylogenetic analyses were performed with MEGA5 software (Tamura et al., 2011) using the Neighbor-Joining method (Saitou and Nei, 1987).

\section{RNA extraction, cDNA synthesis, and real-time polymerase chain reaction}

Trizol (Invitrogen, Carlsbad, CA, USA) was used to extract total RNA from tissue samples (skeletal muscle, kidney, thyroid, lung, appendix, colon, spinal cord, and heart) and leukocytes from horses after exercise according to manufacturer instructions. Total RNA was quantified by NanoDrop spectrophotometer (Thermo Fisher Scientific Inc., Waltham, MA, USA). The horse ADRB2 transcript was analyzed by real-time polymerase chain reaction (RT-PCR) amplification. The primers were designed with PRIMER3 software (http://frodo. wi.mit.edu/primer3/). The RT-PCR conditions were as follows: an initial step at $94^{\circ} \mathrm{C}$ for 10 min; 35 cycles at $94^{\circ} \mathrm{C}$ for $30 \mathrm{~s}, 60^{\circ} \mathrm{C}$ for $30 \mathrm{~s}$, and $72^{\circ} \mathrm{C}$ for $30 \mathrm{~s}$; and a final step at $72^{\circ} \mathrm{C}$ for $10 \mathrm{~min}$. The RT-PCR products were analyzed by electrophoresis on a $2.0 \%$ Seakem LE agarose gel (Lonza, Basel, Switzerland). PCR products were normalized against the glyceraldehyde 3phosphate dehydrogenase $(G A P D H)$ gene.

\section{Quantitative real-time polymerase chain reaction analysis}

Quantitative RT-PCR (qPCR) was conducted to analyze expression of $A D R B 2$ with a CFX-96 RT-PCR detection system (BioRad, Hercules, CA, USA). The PCR conditions were as follows: an initial step at $94^{\circ} \mathrm{C}$ for $3 \mathrm{~min} ; 39$ cycles at $94^{\circ} \mathrm{C}$ for $10 \mathrm{~s}, 60^{\circ} \mathrm{C}$ for $30 \mathrm{~s}$, and $72^{\circ} \mathrm{C}$ for $30 \mathrm{~s}$; and a final step at $72^{\circ} \mathrm{C}$ for $10 \mathrm{~min}$. Dissociation was performed at $0.5^{\circ} \mathrm{C}$ increments from $55^{\circ} \mathrm{C}$ to $95^{\circ} \mathrm{C}$ for over $25 \mathrm{~min}$. All samples were measured in triplicates to ensure reproducibility, and $C_{t}$ values were calculated by the $2^{-\Delta \Delta C t}$ method (Livak and Schmittgen, 2001). The GAPDH gene was used for reference.

\section{Statistical analysis}

Both T-test and analysis of variance statistical test was conducted to determine significance levels. Data were shown by mean \pm standard error of mean.

\section{RESULTS AND DISCUSSION}

The horse $A D R B 2$ gene sequences were obtained from both whole genome sequencing and RNA-seq (Park et al., 2012). To compare the horse $A D R B 2$ gene with other animals, $A D R B 2$ genes were retrieved from the Ensemble database. In the prediction study, horse ADRB2 is a $G$ protein-coupled receptor with rhodopsin-like domain with 7 transmembrane domains, and the amino acid sequences within these domains were conserved well compared to the sequences outside the domains (Figure 1A). This indicates that the horse $A D R B 2$ gene has the same biological functions as $A D R B 2$ in other animals. High similarity was found with human and chimpanzee, while low similarity was found in chicken (Figure 1B). In the analysis of genomic structure, horse $A D R B 2$ was encoded on a single copy of gene and had a single exon without intron. The substitution ratio of non-synonymous (Ka)/synonymous (Ks) nucleotides was less than one (Table 1). Assuming that protein-coding regions in the human genome are under positive selection during evolution (Bustamante et al., 2005), these results illustrate that non-synonymous substitutions occurred faster than synonymous substitutions and that positive selection occurred in the $A D R B 2$ gene 
(A)
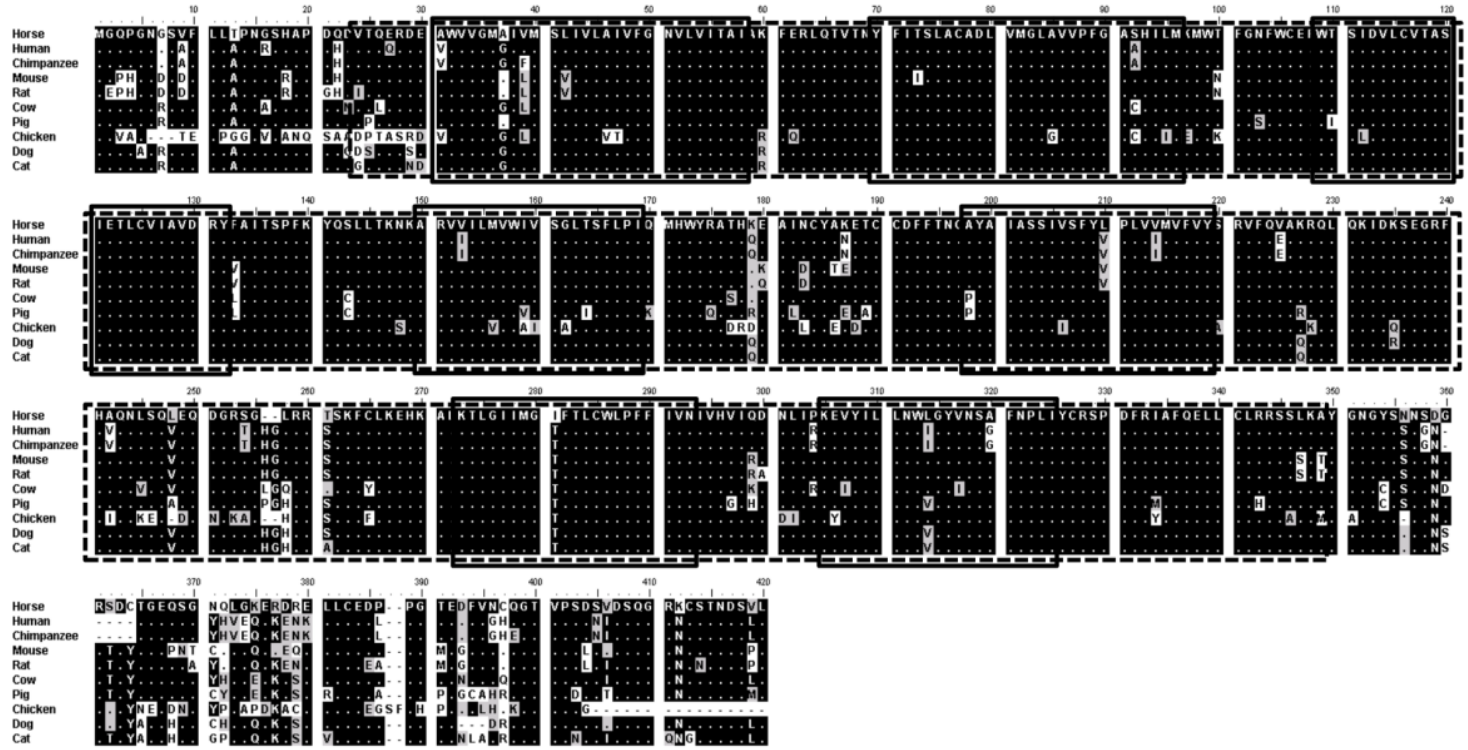

(B)

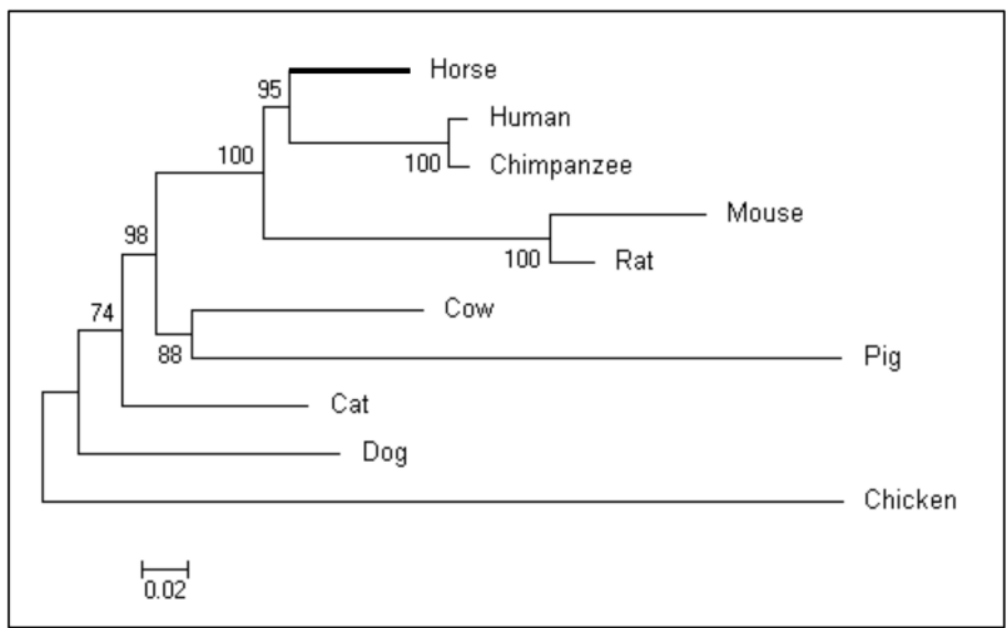

Figure 1. Sequence analysis of horse $A D R B 2$ gene. (A) Alignment of amino acid sequences of the ADRB2 gene in various species. The domains of $\mathrm{G}$ protein-coupled receptor, rhodopsin-like (dashed box) and 7 transmembrane (solid boxes) are conserved well between the species. (B) Phylogenetic analysis the $A D R B 2$ gene in various species. The phylogenetic tree for the $A D R B 2$ gene in various species was obtained by the neighbor-joining method and bootstrap 1000. ADRB2, adrenergic receptor beta 2 .

Table 1. Synonymous (Ks) and non-synonymous (Ka) substitutions per site in the ADRB2 gene of various species

\begin{tabular}{lccccccccccc}
\hline Ka/Ks & 1 & 2 & 3 & 4 & 5 & 6 & 7 & 8 & 9 & 10 \\
\hline 1. Horse & & 0.143 & 0.143 & 0.260 & 0.229 & 0.223 & 0.364 & 0.531 & 0.145 & 0.184 \\
2. Human & 0.102 & & 0.013 & 0.282 & 0.202 & 0.252 & 0.416 & 0.544 & 0.198 & 0.207 \\
3. Chimpanzee & 0.104 & 0.019 & & 0.282 & 0.204 & 0.253 & 0.419 & 0.543 & 0.194 & 0.209 \\
4. Mouse & 0.189 & 0.226 & 0.225 & & 0.087 & 0.384 & 0.583 & 0.601 & 0.326 & 0.321 \\
5. Rat & 0.157 & 0.144 & 0.148 & 0.055 & & 0.322 & 0.482 & 0.593 & 0.260 & 0.280 \\
6. Cow & 0.158 & 0.182 & 0.189 & 0.244 & 0.199 & & 0.336 & 0.553 & 0.247 & 0.206 \\
7. Pig & 0.324 & 0.360 & 0.367 & 0.452 & 0.370 & 0.274 & & 0.737 & 0.388 & 0.246 \\
8. Chicken & 0.414 & 0.416 & 0.418 & 0.452 & 0.428 & 0.422 & 0.586 & & 0.510 & 0.509 \\
9. Dog & 0.113 & 0.156 & 0.158 & 0.241 & 0.162 & 0.178 & 0.338 & 0.393 & & 0.160 \\
10. Cat & 0.144 & 0.177 & 0.181 & 0.233 & 0.190 & 0.138 & 0.221 & 0.406 & 0.158 & \\
\hline ADRB2, & & & & & & & & & &
\end{tabular}

ADRB2, adrenergic receptor beta 2 .

Average of Ka ratio was 0.324 and Ks ratio was 0.249 . 
during evolution in the horse. This ratio also demonstrates profitable evolution of the ADRB2 gene in various species.

The RT-PCR and qPCR analyses showed that the horse $A D R B 2$ gene is expressed in various tissues such as skeletal muscle, kidney, thyroid, lung, appendix, colon, spinal cord, and heart (Figure 2A). Among these tissues, the expression of $A D R B 2$ gene was highest in lung, while lowest in skeletal muscle and appendix. Next, the expression pattern of $A D R B 2$ gene after exercise was analyzed in skeletal muscle and leukocytes (Figure 2B). Expression in muscle was significantly increased after $30 \mathrm{~min}$ of exercise. In leukocytes, the expression of $A D R B 2$ gene increased after 30 and $60 \mathrm{~min}$ of exercise, but decreased from $90 \mathrm{~min}$ and reached to the basal level after $120 \mathrm{~min}$ of exercise (Figure 2C).

There are substantial published researches on the relations between $A D R B 2$ polymorphisms and physiological phenotypes, especially with regards to lung disease, in human. For example, $A D R B 2$ is expressed in many cell types of lung tissue, and there is a correlation between $A D R B 2$ polymorphisms (Gly16/Arg16 and Glu27/Gln27) and chronic obstructive pulmonary disease (COPD). The frequency of the Arg16 allele was lower in Chinese patients with COPD than in healthy patients (Ho et al., 2001), while the frequency of the Gln27 allele was higher in Egyptian patients with COPD than in healthy patients (Hegab et al., 2004). In the lung health study, 27 smokers with a Glu27/Gln27 heterozygous genotype were protected from lung malfunction compared to a control population with a homozygous genotype (Joos et al., 2003). In this study, any non-synonymous nucleotide substitution of horse ADRB2 was not found. This may due to the small number of horse samples or no existence of non-synonymous nucleotide substitution in horse $A D R B 2$.
(A)

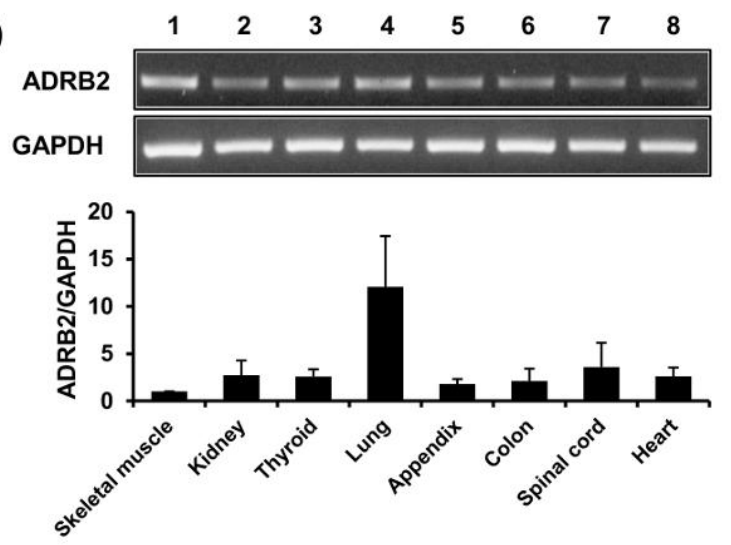

(B)

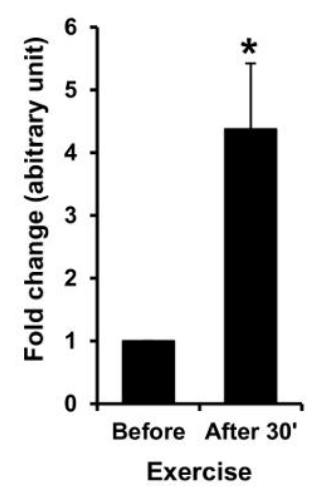

(C)
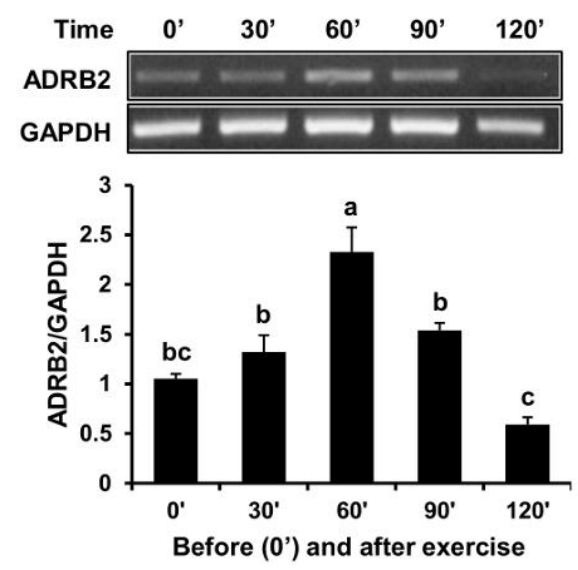

Figure 2. Analysis of the horse $A D R B 2$ gene expression in various tissues and before and after exercise. (A) RT-PCR of the $A D R B 2$ gene in various horse tissues including the skeletal muscle, kidney, thyroid, lung, appendix, colon, spinal cord, and heart (lane 1-8 in order). $A D R B 2$ was expressed in all tested horse tissues. Then the expression level of the $A D R B 2$ gene in various horse tissues by $\mathrm{qPCR}(\mathrm{n}=3$ for each tissues, $\mathrm{p}=0.069$ ). (B) The expression of $A D R B 2$ gene in horse skeletal muscle before and 30 min after exercise. The values of fold change were determined by NGS RNA-sequencing ( $\mathrm{n}=5$ for each group). The ADRB2 gene was expressed higher about 4 folds after exercise (* means p<0.05). (C) The expression of ADRB2 gene in horse leukocytes. The expression level of $A D R B 2$ gene in leukocytes was determined by qPCR. The $A D R B 2$ expression was up-regulated after exercise until 60 min, but decreased afterward and reached to basal level at $120 \min (\mathrm{n}=3, \mathrm{p}<0.001)$. All data were shown as mean \pm standard error of mean. ADRB2, adrenergic receptor beta 2; RT-PCR, real-time polymerase chain reaction; qPCR, quantitative RT-PCR; NGS, next generation sequencing. 
There is some evidence which suggests that $A D R B 2$ gene is related to the endurance and recovery of exercise in humans (Zieker et al., 2005; Wolfarth et al., 2007; MacNeil et al., 2010). The substitution of amino acid from Arg to Gly on the 16th codon of human ADRB2 is unfavorable for endurance performance and frequently found in a sedentary person. In addition, $A D R B 2$ expression is regulated by exercise in muscle and blood cells. Given this information, we analyzed the expression pattern of $A D R B 2$ gene in both skeletal muscle and blood cells pre- and post- exercise in horse. As shown in results, horse $A D R B 2$ expression was regulated depending on the exercise in both cell types, suggesting the $A D R B 2$ gene might respond to stress caused by exercise and might serve as a biomarker for exercise and/or recovery in horse. For further studies, the mechanism and cell signaling pathway that regulates the expression of the $A D R B 2$ gene during exercise should be investigated and, more importantly, the consequences of increased and/or decreased $A D R B 2$ gene expression should be studied at the molecular level. This study provides useful sequence and expression information of the horse $A D R B 2$ gene after exercise, and suggests that $A D R B 2$ gene as an early biomarker for evaluating the status of horse after racing.

\section{ACKNOWLEDGMENTS}

This work was supported by a grant from the Next Generation BioGreen 21 Program (No. PJ011044 and PJ011173), Rural Development Administration, Republic of Korea.

\section{REFERENCES}

Bustamante, C. D., A. Fledel-Alon, S. Williamson, R. Nielsen, M. T. Hubisz, S. Glanowski, D. M. Tanenbaum, T. J. White, J. J. Sninsky, R. D. Hernandez, D. Civello, M. D. Adams, M. Cargill, and A. G. Clark. 2005. Natural selection on proteincoding genes in the human genome. Nature 437:1153-1157.

Hegab, A. E., T. Sakamoto, W. Saitoh, H. H. Massoud, H. M. Massoud, K. M. Hassanein, and K. Sekizawa. 2004. Polymorphisms of IL4,IL13, and ADRB2 genes in COPD. Chest 126:1832-1839.
Ho, L. I., H. J. Harn, C. J. Chen, and N. M. Tsai. 2001. Polymorphism of the beta(2)-adrenoceptor in COPD in Chinese subjects. Chest 120:1493-1499.

Joos, L., T. D. Weir, J. E. Connett, N. R. Anthonisen, R. Woods, P. D. Pare, and A. J. Sandford. 2003. Polymorphisms in the beta2 adrenergic receptor and bronchodilator response, bronchial hyperresponsiveness, and rate of decline in lung function in smokers. Thorax 58:703-707.

Livak, K. J. and T. D. Schmittgen. 2001. Analysis of relative gene expression data using real-time quantitative PCR and the 2(Delta Delta C(T)) method. Methods 25:402-408.

MacNeil, L. G., S. Melov, A. E. Hubbard, S. K. Baker, and M. A. Tarnopolsky. 2010. Eccentric exercise activates novel transcriptional regulation of hypertrophic signaling pathways not affected by hormone changes. PLoS ONE 5(5):e10695.

McGraw, D. W. and S. B. Liggett. 2005. Molecular mechanisms of beta2-adrenergic receptor function and regulation. Proc. Am. Thorac. Soc. 2:292-296.

Park, K. D., J. Park, J. Ko, B. C. Kim, H. S. Kim, K. Ahn, K. T. Do, H. Choi, H. M. Kim, S. Song, S. Lee, S. Jho, H. S. Kong, Y. M. Yang, B. H. Jhun, C. Kim, T. H. Kim, S. Hwang, J. Bhak, H. K. Lee, and B. W. Cho. 2012. Whole transcriptome analyses of six thoroughbred horses before and after exercise using RNA-Seq. BMC Genomics 13:473.

Rang, H. P., M. M. Dale, J. M. Ritter, and P. K. Moore. 2003. Pharmacology. 5th ed. Churchill Livingstone, Edinburgh, Scotland.

Saitou, N. and M. Nei. 1987. The neighbor-joining method: a new method for reconstructing phylogenetic trees. Mol. Biol. Evol. 4:406-425.

Tamura, K., D. Peterson, N. Peterson, G. Stecher, M. Nei, and S. Kumar. 2011. MEGA5: molecular evolutionary genetics analysis using maximum likelihood, evolutionary distance, and maximum parsimony methods. Mol. Biol. Evol. 28:2731-2739.

Wolfarth, B., T. Rankinen, S. Muhlbauer, J. Scherr, M. R. Boulay, L. Perusse, R. Rauramaa, and C. Bouchard. 2007. Association between a beta2-adrenergic receptor polymorphism and elite endurance performance. Metabolism. 56:1649-1651.

Zieker, D., J. Zieker, J. Dietzsch, M. Burnet, H. Northoff, and E. Fehrenbach. 2005. CDNA-microarray analysis as a research tool for expression profiling in human peripheral blood following exercise. Exerc. Immunol. Rev. 11:86-96. 